DOI: https://doi.org/10.24127/ajpm.v10i1.2140

\title{
HANDBOOK ARITMATIKA SOSIAL DENGAN PENDEKATAN NILAI-NILAI ISLAM
}

\author{
Septi Hardiyanti ${ }^{1}$, Nurul Farida ${ }^{2^{*}}$, Nurain Suryadinata ${ }^{3}$ \\ 1,2* Universitas Muhammadiyah Metro, Metro, Indonesia \\ ${ }^{3}$ Universitas Lampung, Bandar Lampung, Indonesia \\ *Corresponding author. \\ E-mail: $\quad \frac{\text { septihardiyanti0909@gmail.com }}{\text { nurulfaridamath@gmail.com }}{ }^{\left.2^{*}\right)}$ \\ $\underline{\text { nurain.suryadinata@fkip.unila.ac.id }}{ }^{3)}$
}

Received 29 March 2020; Received in revised form 18 December 2020; Accepted 31 March 2021

\begin{abstract}
Abstrak
Tujuan penelitian ini adalah mengembangkan bahan ajar yang layak (valid dan praktis) berbentuk handbook dengan menggunakan pendekatan nilai-nilai islam pada materi aritmatika sosial. Jenis penelitian yang digunakan adalah Research and Development (R\&D) dengan langkah-langkah: potensi dan masalah, pengumpulan data, desain produk, validasi desain, revisi desain, uji coba produk, revisi produk, uji coba pemakaian, revisi produk, produk masal. Instrumen penelitian yang digunakan adalah lembar angket validasi, lembar angket respon siswa dan lembar angket respon guru. Berdasarkan hasil validasi dengan persentase penilaian dari aspek materi dan bahasa 84,2\% dikategorikan sangat valid, aspek agama $81,8 \%$ dikategorikan sangat valid, dan aspek desain 78,8\% dikategorikan valid, dan rata-rata penilaian validator adalah $81,4 \%$ dengan kategori sangat valid. Sedangkan dari hasil uji coba pemakaian diperoleh rata-rata angket respon yang diberikan oleh 1 guru dan 18 peserta didik sebesar 84,3\% dikategorikan sangat layak. Berdasarkan kriteria yang telah ditetapkan maka bahan ajar berbentuk handbook dengan menggunakan pendekatan nilai-nilai islam pada materi aritmatika sosial yang dikembangkan memenuhi kriteria valid dan praktis, menurut validator dan peserta didik.
\end{abstract}

Kata kunci: Aritmatika sosial; bahan ajar; handbook; nilai-nilai Islam.

\begin{abstract}
The purpose of this research is to develop appropriate (valid and practical) teaching materials in the form of a handbook using the Islamic values approach to social arithmetic material. The type of research is research and development $(R \& D)$ with steps to use are research and information collecting, planning, develop preliminary from the product, preliminary field testing, main product revision, main field testing, operational product revision, operational field testing, final product revision, and dissemination and implementation. Based on the results of the validation with the percentage of assessment from the material and language aspects $84.2 \%$ were categorized as very valid, $81.8 \%$ religious aspects were categorized as very valid, and $78.8 \%$ design aspects were categorized as valid, and the average validator assessment was $81.4 \%$ with very valid categories. Whereas from the results of the trial use, the average response questionnaire given by 1 teacher and 18 students at $84.3 \%$ was categorized as very feasible. Based on the established criteria, the teaching material in the form of a handbook using the Islamic values approach to social arithmetic material developed meets valid and practical criteria, according to the validator and students.
\end{abstract}

Keywords: Social arithmetics; teaching material; handbook; Islamic values.

This is an open access article under the Creative Commons Attribution 4.0 International License 
DOI: https://doi.org/10.24127/ajpm.v10i1.2140

\section{PENDAHULUAN}

Salah satu materi matematika di sekolah yang cukup banyak penerapannya dalam kehidupan seharihari adalah Aritmatika sosial. Materi tersebut dipelajari siswa di kelas VII. Kajian yang ada di dalam aritmetika sosial diataranya terkait jual beli, untung rugi, bunga, bruto, dan sebagainya. Menurut Heryuriani \& Musdayati (2020), materi aritmetika cukup esensial di dalam pembelajaran matematika khususnya di kelas VII, sehingga siswa diharapkan dapat menguasainya dan dapat menerapkan dalam kehidupan sehari-hari.

Pembelajaran matematika dengan materi aritmatika sosial dapat digabungkan dengan penanaman karakter kepada siswa, termasuk karakter terkait nilai-nilai Islam. Menurut Kurniati (2015), jika dapat mengintegrasikan Islam dari setiap konsep matematika tentunya akan lebih mudah mengembangkannya dalam setiap proses pembelajaran.

Pentingnya integrasi matematika dengan nilai-nilai Islam juga dijelaskan oleh Maarif (2015); Khoiriyah \& Rizki (2017) bahwasannya pengintegrasian konsep matematika dengan nilai-nilai keislaman sangat penting untuk diterapkan karena merupakan salah satu cara membentuk karakter bangsa, sehingga perlu dikembangkan secara terus menerus. Implikasi lainnya adalah menjadikan siswa lebih mandiri dalam belajar matematika serta menjadikan siswa yakin terhadap kebenaran (Khamidah, 2013).

Namun demikian, ternyata masih terdapat siswa yang mengalami kesulitan dalam mempelajari materi aritmatika sosial (Widyaningrum, 2016; Sari, Susanti, \& Rahayu, 2018; Andayani \& Lathifah, 2019). Hal ini juga ditemukan di MTs Al-Istiqomah
Giri Mulyo, di mana siswa masih kesulitan dalam mengubah permasalahan dalam bentuk cerita menjadi bentuk model matematika.

Selain itu berdasarkan hasil wawancara dengan guru bidang studi matematika dan angket yang ditujukan untuk peserta didik MTs Al-Istiqomah Giri Mulyo diperoleh informasi bahwa di sekolah sudah menerapkan pembelajaran berbasis islam. Hal tersebut dikarenakan sekolah tersebut merupakan sekolah berbentuk madrasah yang menekankan pelajaran keislaman, seperti pembelajaran bahasa arab, akidah akhlak, serta ilmu fikih. Namun demikian, ada kesulitan bagi guru di luar pelajaran agama untuk dapat mengintegrasikan nilai-nilai islam tersebut, salah satunya di pelajaran matematika. Hal ini dikarenakan guru mengalami kesulitan dalam mencari integrasi konsep matematika dengan nilai-nilai islam yang sesuai.

Salah satu cara untuk mengatasi kesulitan belajar adalah dengan melakukan pengembangan bahan ajar yang sesuai kebutuhan. Menurut Fitriyah, Santoso, \& Suryadinata (2018), salah satu alternatif dalam mengatasi kesulitan belajar siswa adalah dengan melakukan pengembangan bahan ajar. Selain itu, pengembangan bahan ajar juga dapat digunakan untuk meningkatkan kemampuan pemecahan masalah siswa (Siniguian, 2017).

Selanjutnya, integrasi nilai-nilai Islam juga dapat dilakukan melalui bahan ajar yang dikembangkan. Artinya penyampaian nilai-nilai Islam tidak hanya melalui ucapan guru saja, namun juga melalui bahan ajar yang dibuat sehingga pada saat belajar mandiri pun siswa dapat memperoleh konsep matematika itu sendiri ditambah dengan nilai-nilai Islam. 
Penelitian terkait pengembangan bahan ajar yang diintegrasikan dengan nilai-nilai Islam sudah cukup banyak dilakukan (Khoiriyah \& Rizki, 2017; Pratiwi, 2019; Pamungkas, Rizki, \& Vahlia, 2020), namun masih sedikit yang berfokus pada aritmetika sosial. Sedangkan penelitian Rahmawati \& Rizki (2017) sudah mengembangkan bahan ajar Aritmetika Sosial dengan nilai Islam, namun demikian fokusnya masih pada ayat Al-Quran, dan baru diintegrasikan di bagian materi. Jadi pada penelitian ini akan dikembangkan bahan ajar dalam bentuk Handbook dengan fokus materi di Aritmetika Sosial dengan pendekatan nilai-nilai Islam yang diambil dari Al Quran dan
Hadits, selain itu integrasi nilai-nilai tersebut tidak hanya di materi namun juga pada soal-soal latihan.

\section{METODE PENELITIAN}

Penelitian ini merupakan penelitian dan pengembangan yang bertujuan untuk menghasilkan produk baru dengan kriteria-kriteria tertentu. Model pengembangan yang digunakan dalam penelitian ini menggunakan mengadaptasi model Research and Development (R\&D) (Sugiyono, 2012). Berikut langkah-langkah pengembangan model Research and Development (R\&D). Langkah-langkah metode R\&D yang digunakan dapat dilihat pada Gambar 1.

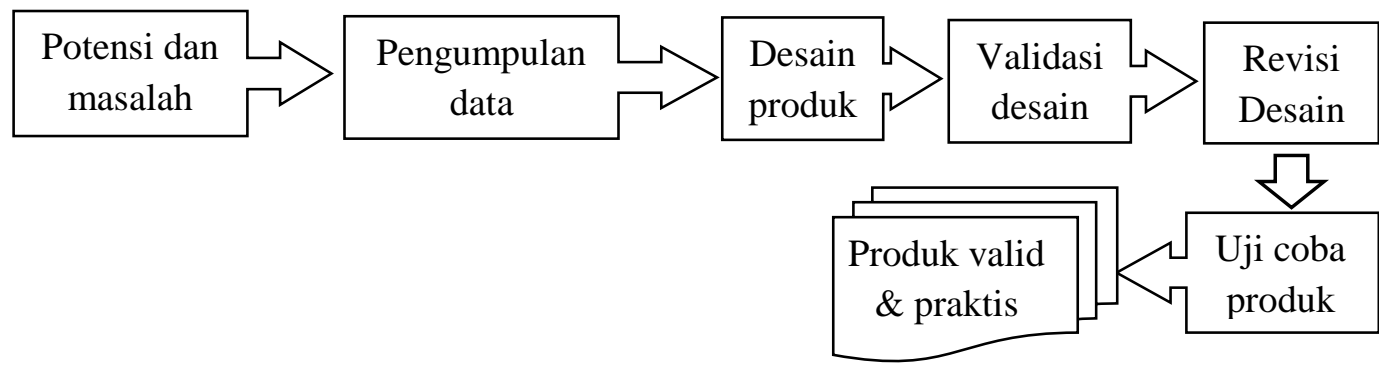

Gambar 1. Langkah-langkah penggunaan metode research and development (R\&D)

Subjek uji coba yang digunakan pada penelitian ini adalah peserta didik kelas VII MTs Al-Istiqomah Giri Mulyo. Uji coba dilakukan pada peserta didik kelas VII A, dengan jumlah 18 peserta didik dan 1 guru bidang studi matematika, untuk mengetahui respon dalam penggunaan bahan ajar.

Instrumen pengumpulan data yang digunakan adalah: (1) angket validasi ahli materi dan bahasa yang digunakan untuk menilai kualitas dan kelengkapan materi serta menilai tata bahasa yang digunakan; (2) angket validasi ahli desain, yang digunakan untuk menilai desain atau tampilan handbook serta tata letak objeknya; (3) angket validasi ahli agama, yang digunakan untuk menilai kebenaran nilai-nilai Islam yang digunakan; dan (4) angket kepraktisan, digunakan untuk melihat respon siswa terhadap handbook yang dikembangkan.

Perhitungan untuk analisis data validitas dan kepraktisan produk menggunakan rumus seperti rumus 1 berikut.

skor $\left.=\frac{\sum \text { Skor Perindikator }}{\sum \text { Skor Maksimal Indikator }} \times 100 \% \ldots 1\right)$

Selanjutnya, hasil dari perhitungan skor validitas dan reliabilitas diinterpretasikan ke dalam kualitatif sesuai dengan kriteria seperti yang tercantum pada Tabel 1. 
DOI: https://doi.org/10.24127/ajpm.v10i1.2140

Tabel 1. Kriteria produk.

\begin{tabular}{cc}
\hline Skor $(\boldsymbol{\%})$ & Kriteria \\
\hline $81,00-100,00$ & Sangat valid/Praktis \\
\hline $61,00-80,00$ & Valid/Praktis \\
\hline $41,00-60,00$ & Cukup valid/Praktis \\
\hline $21,00-40,00$ & Kurang valid/Praktis \\
\hline $00,00-20,00$ & Tidak valid/Praktis \\
\hline
\end{tabular}

\section{HASIL DAN PEMBAHASAN}

Tahap pertama pada pengembangan ini adalah menganalisis potensi dan masalah. Berdasarkan analisis tersebut maka diperlukan bahan ajar aritmetika sosial dengan nilai-nilai Islam yang berbentuk Handout. Selanjutnya dilakukan pengumpulan data untuk menyusun draf bahan ajar tersebut. Data-data yang dikumpulkan terkait kurikulum, materi, referensi terkait nilai-nilai Islam, serta analisis karakteristik siswa.

Selanjutnya dilakukan tahap desain produk, yaitu menyusun draf Handout aritmetika sosial dengan nilainilai Islam. Pada Handout tersebut dicantumkan materi, contoh soal, dan latihan soal serta dimasukkan juga nilainilai Islam dengan mengambil dari potongan ayat AlQuran atau Hadits.

Pada tahap validasi desain, Handout divalidasi oleh sembilan orang validator yang terdiri dari tiga validator materi dan bahasa, tiga validator agama Islam, dan tiga validator desain. Hasil validasi pertama validasi oleh ahli materi dan bahasa yang dapat dilihat pada Tabel 2.

Tabel 2. Rekapitulasi hasil validasi ahli materi dan bahasa

\begin{tabular}{|c|c|c|c|c|c|c|}
\hline \multirow{2}{*}{ Aspek } & \multirow{2}{*}{ Kriteria } & \multicolumn{3}{|c|}{ Skor } & \multirow{2}{*}{$\begin{array}{c}\text { Persentase } \\
(\%)\end{array}$} & \multirow{2}{*}{ Kategori } \\
\hline & & V1 & $\mathrm{V} 2$ & V3 & & \\
\hline Materi dan & 1 & 5 & 4 & 5 & $93,3 \%$ & Sangat Valid \\
\hline \multirow[t]{15}{*}{ Bahasa } & 2 & 5 & 4 & 5 & $93,3 \%$ & Sangat Valid \\
\hline & 3 & 5 & 3 & 5 & $86,7 \%$ & Sangat Valid \\
\hline & 4 & 4 & 3 & 3 & $66,7 \%$ & Cukup Valid \\
\hline & 5 & 4 & 4 & 3 & $73,3 \%$ & Valid \\
\hline & 6 & 5 & 3 & 4 & $80,0 \%$ & Valid \\
\hline & 7 & 4 & 4 & 4 & $80,0 \%$ & Valid \\
\hline & 8 & 4 & 5 & 4 & $86,7 \%$ & Sangat Valid \\
\hline & 9 & 4 & 4 & 3 & $73,3 \%$ & Valid \\
\hline & 10 & 5 & 5 & 4 & $93,3 \%$ & Sangat Valid \\
\hline & 11 & 4 & 5 & 4 & $86,7 \%$ & Sangat Valid \\
\hline & 12 & 4 & 3 & 4 & $73,3 \%$ & Valid \\
\hline & 13 & 4 & 5 & 4 & $86,7 \%$ & Sangat Valid \\
\hline & 14 & 5 & 5 & 3 & $86,7 \%$ & Sangat Valid \\
\hline & 15 & 4 & 5 & 4 & $86,7 \%$ & Sangat Valid \\
\hline & 16 & 5 & 5 & 5 & $100,0 \%$ & Sangat Valid \\
\hline Jumlah & \multicolumn{4}{|c|}{202} & & \\
\hline Rata-rata & & & & & $84,2 \%$ & \\
\hline
\end{tabular}

Keterangan: V1= Validator 1, V2= Validator 2, V3= Validator 3

Tabel 2 menunjukkan hasil penilaian tiga validator materi dan bahasa, dimana terdapat 16 item pertanyaan yang diberikan skor skala 15. Secara keseluruhan persentase penilaian materi dan bahasa berada di 
angka $82,2 \%$ atau dalam kategori sangat valid.

Saran perbaikan yang diberikan ahli materi antara lain terkait dengan penulisan rumus, di mana terdapat dua rumus yang bersimbol sama, namun dalam penerapan rumus tersebut berbeda dan dapat membuat siswa kesulitan dalam penerapannya. Sehingga dari tim validator memberikan saran agar dapat merevisi bagian rumus yang dapat memberikan perbedaan yang dapat dipahami siswa. Selain itu keterkaitan gambar juga belum sesuai dengan materi sehingga pada tahap revisi produk juga dilakukan pergantian gambar yang sesuai dengan materi yang disampaikan.

Hasil validasi selanjutnya adalah hasil validasi oleh ahli agama Islam yang disajikan pada Tabel 3.

Tabel 3. Rekapitulasi hasil validasi ahli agama.

\begin{tabular}{lcccccc}
\hline \multirow{2}{*}{ Aspek } & \multirow{2}{*}{ Kriteria } & \multicolumn{3}{c}{ Skor } & Persentase & Kategori \\
\cline { 2 - 5 } & $\mathbf{V 1}$ & $\mathbf{V 2}$ & $\mathbf{V 3}$ & $\mathbf{( \% )}$ & Sangat Valid \\
Agama Islam & 1 & 5 & 4 & 4 & $86,7 \%$ & Valid \\
& 2 & 5 & 3 & 3 & $73,3 \%$ & Sangat Valid \\
& 3 & 4 & 5 & 4 & $86,7 \%$ & Valid \\
& 4 & 4 & 4 & 4 & $80 \%$ & Valid \\
& 5 & 4 & 4 & 3 & $73,3 \%$ & Sangat Valid \\
& 6 & 5 & 4 & 5 & $93,3 \%$ & Sangat Valid \\
& 7 & 5 & 3 & 4 & $86,7 \%$ & Valid \\
& 8 & 5 & 5 & 4 & $93,3 \%$ & Sangat Valid \\
& 9 & 4 & 4 & 3 & $73,3 \%$ & Valid \\
\hline Jumlah & 10 & 5 & 4 & 4 & $86,7 \%$ & Sangat Valid \\
\hline Rata-rata & 11 & 4 & 3 & 4 & $73,3 \%$ & \\
\hline Kategori & & \multicolumn{7}{c}{} & $\mathbf{8 1 , 8 \%}$ & \\
\hline
\end{tabular}

Keterangan: V1= Validator $1, \mathrm{~V} 2=$ Validator $2, \mathrm{~V} 3=$ Validator 3

Hasil validasi yang disajikan pada Tabel 3 menunjukkan bahwa berdasarkan hasil penilaian tiga validator ahli nilainilai agama Islam, terdapat 11 item pertanyaan yang diberikan skor skala 15. Secara keseluruhan persentase penilaian nilai-nilai Islam berada di angka $81,8 \%$ atau dalam kategori sangat valid. Akan tetapi, tetap ada beberapa saran yang disampaikan oleh ahli agama Islam untuk memperbaiki produk hasil pengembangan.

Saran perbaikan yang diberikan ahli agama Islam antara lain adalah agar dapat mengganti riwayat hadits yang berkesesuaian tentang sub materi yang disampaikan. Setelah melalui tahap revisi, riwayat hadis tersebut telah diganti dengan riwayat hadis yang berkesesuaian dan sahih. Saran lainnya yaitu penambahan sumber hadist, penggunaan doa dan pengutipan ayat agar bisa disamakan ukuran font nya serta penggantian background agar tampilan tampak sama dengan background pada ayat lainnya.

Setelah melekukan validasi terhadap ahli agama Islam, validasi dilanjutkan ke ahli desain. Hasil validasi dari ahli desain dapat dilihat pada Tabel 4. 
DOI: https://doi.org/10.24127/ajpm.v10i1.2140

Tabel 4. Rekaptulasi hasil validasi ahli desain.

\begin{tabular}{lcccccc}
\hline \multirow{2}{*}{ Aspek } & \multirow{2}{*}{ Kriteria } & \multicolumn{3}{c}{ Skor } & $\begin{array}{c}\text { Persentase } \\
(\mathbf{\%})\end{array}$ & Kategori \\
\cline { 2 - 4 } & $\mathbf{V 1}$ & $\mathbf{V 2}$ & $\mathbf{V 3}$ & & Cukup Valid \\
& 1 & 3 & 3 & 4 & $66,7 \%$ & Valid \\
& 2 & 4 & 4 & 4 & $80 \%$ & Sangat Valid \\
& 3 & 4 & 4 & 5 & $86,7 \%$ & Valid \\
& 4 & 4 & 3 & 4 & $73,3 \%$ & Sangat Valid \\
& 5 & 4 & 4 & 5 & $86,7 \%$ & Sangat Valid \\
& 6 & 4 & 5 & 5 & $93,3 \%$ & Valid \\
& 7 & 4 & 4 & 4 & $80 \%$ & Valid \\
& 8 & 3 & 4 & 4 & $73,3 \%$ & Valid \\
& 9 & 4 & 4 & 4 & $80 \%$ & Valid \\
\hline Jumlah & 10 & 4 & 3 & 4 & $73,3 \%$ & Valid \\
\hline Rata-rata & 11 & 4 & 3 & 4 & $73,3 \%$ & \\
\hline Kategori & \multicolumn{7}{c}{130} & & & \\
\hline
\end{tabular}

Keterangan: V1= Validator 1, V2= Validator 2, V3= Validator 3

Tabel 4 menunjukkan hasil penilaian tiga validator desain, dimana terdapat 11 item pertanyaan yang diberikan skor skala 1-5. Secara keseluruhan persentase penilaian desain berada di angka $78,8 \%$ atau dalam kategori valid. Saran perbaikan yang diberikan validator desain diantaranya penggunaan spasi yang belum konsisten, cover bahan ajar yang perlu diganti dengan kosep nyata yang berkaitan dengan materi serta kelengkapan idenitas pada cover.

Setelah melalui tahap Validasi, selanjutnya dilakukan tahap Revisi Desain atau Produk berdasarkan saransaran yang diberikan oleh validator. Pada Handbook yang dikembangkan, sudah ditambahkan hadits-hadits yang lebih banyak dan juga dicantumkan riwayat atau sumbernya dengan benar. Contoh tampilan hadist dalam handout yang dikembangkan dapat dilihat pada Gambar 2.

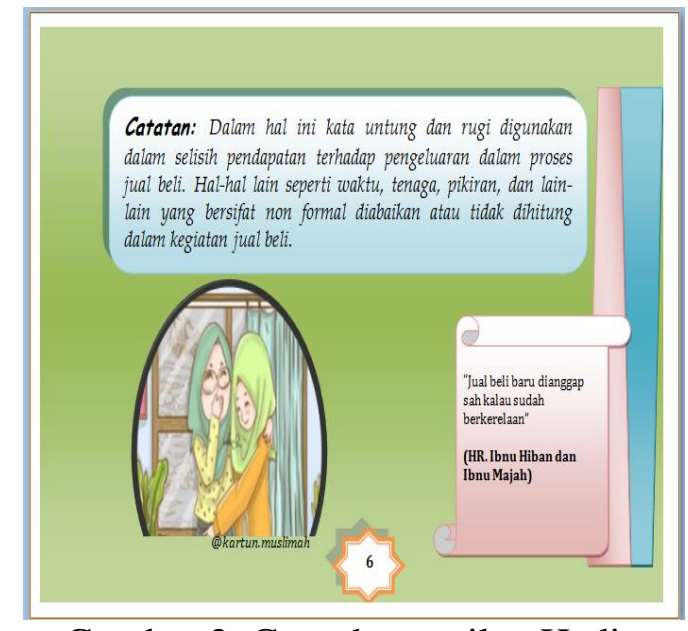

Gambar 2. Contoh tampilan Hadits.

Pada Gambar 2 terlihat hasil revisi yang sudah dilakukan di mana pada awalnya belum terdapat riwayat pada hadits dan selanjutnya diganti dengan hadits dengan riwayat yang jelas. Handout yang dikembangkan dilengkapi dengan tulisan-tulisan arab sebagai ciri utama dari handout yang berisi nilai-nilai Islam. Contoh bagian handout yang berisi tulisan arab dapat dilihat pada Gambar 3. 


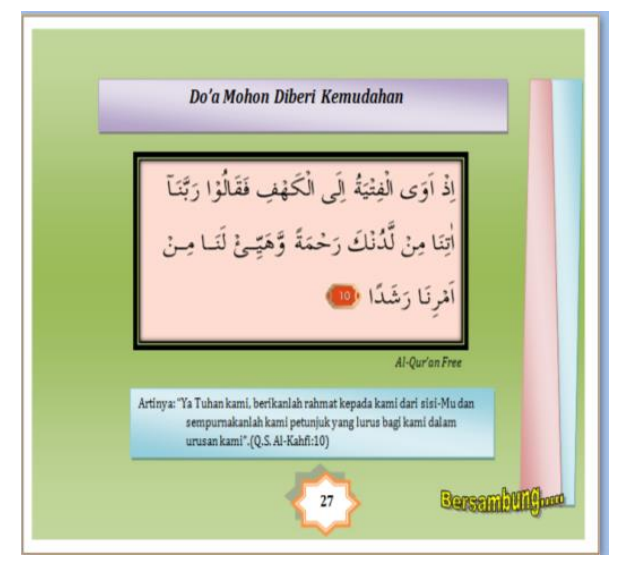

Gambar 3. Contoh tampilan font arab.

Gambar 3 menampilkan cuplikan Ayat Alquran dengan Font Arab yang lebih jelas di mana sebelumnya font tersebut belum jelas dan sulit dibaca. Selanjutnya adalah revisi pada tampilan cover yang sudah lebih disederhanakan dan gambar yang digunakan adalah gambar yang sesuai dengan materi yang disampaikan dalam handbook, jadi dipilih gambar kegiatan di pasar yaitu jual beli, serta identitas pada cover sudah dilengkapi. Hasil revisi pada bagian cover dapat dilihat pada Gambar 4.

Tabel 5. Rekapitulasi hasil uji kepraktisan.

\begin{tabular}{cccccc}
\hline No & Subjek & Jumlah & $\begin{array}{c}\text { Persentase } \\
\text { kepraktisan }\end{array}$ & Rata-Rata & Keterangan \\
\hline 1 & Guru & 1 & $84 \%$ & $84,3 \%$ & Sangat \\
2 & Siswa & 18 & $78,8 \%$ & Praktis \\
\hline
\end{tabular}

Berdasarkan Tabel 5 diketahui bahwa rata-rata persentase kepraktisan berada di nilai $84,3 \%$ yang berada pada kategori Sangat Praktis. Hal ini menunjukkan bahwa handbook yang dikembangakan dapat digunakan dalam kegiatan pembelajaran matematika khsusunya pada materi aritmatika sosial.

Selama kegiatan uji coba dalam pembelajaran, siswa antusias mengikuti proses pembelajaran, siswa terlihat

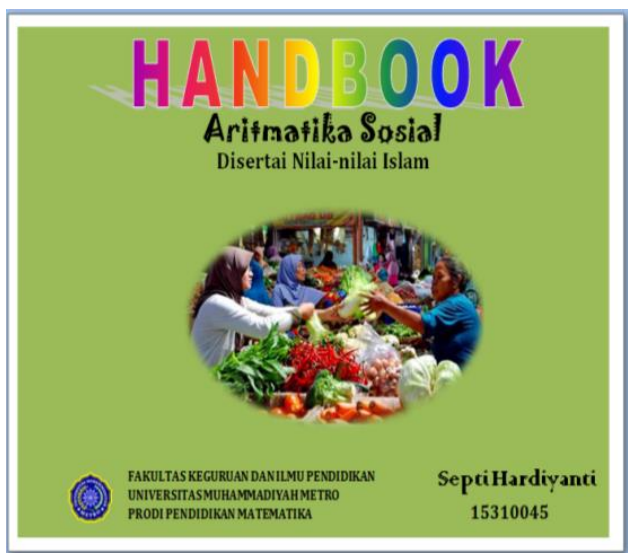

Gambar 4. Tampilan cover.

Selanjutnya masuk pada tahap uji coba produk yang dilakukan terhadap 18 siswa dan 1 guru matematika yang dilakukan di MTs Al-Istiqomah Giri Mulyo. Pada kegiatan uji coba ini diamati kegiatan pembelajaran terbatas yang dilakukan guru dan siswa menggunakan Handbook aritmetika sosial dengan nilai-nilai Islam. Setelah dilakukan ujicoba terbatas ini, kemudian guru dan siswa diberikan angket respon untuk melihat kepraktisan produk yang dikembangkan. Hasil dari uji kepraktisan dapat dilihat pada Tabel 5. 
secara tidak langsung pemahaman siswa terkait Islam akan bertambah dan berdampak ke afektif dan psikomotornya. Hal tersebut sesuai dengan pendapat Ulya \& Hayati (2020) yang mengatakan bahwa perlu adanya perkembangan pola pikir dan dukungan dari berbagai pihak baik pendidik; guru maupun peneliti, stakeholders, lembaga sekolah, LPTK dan ahli pembelajaran matematika bahwa pencapaian tujuan pembelajaran matematika juga penting untuk menanamkan nilai Islami yang berimplikasi ke aspek afektif dan psikomotor.

Nilai-Nilai Islam yang ada pada Handbook tidak hanya cuplikan sekilas saja seperti doa atau motivasi, namun juga ada yang memang dikaitkan dengan materi. Menurut Huda \& Mutia (2017) matematika itu sendiri memiliki hubungan yang sangat erat dengan tradisi spiritual umat Islam dan akrab dengan al-Qur'an. Sebagai contoh pada Handbook terdapat Ayat AlQuran dan Hadits yang membahas tentang jual beli dan hal tersebut sesuai dengan materi yang dibahas yaitu terkait dengan jual beli, karena jual beli menjadi sub materi di dalam aritmetika sosial.

Menurut Salafudin (2015) bahwa nilai-nilai Islam yang diintegrasikan ke dalam mata pelajaran matematika meliputi: 1) nilai akidah, 2) nilai syari'ah, dan 3) nilai akhlak. Untuk Handbook yang dikembangkan memang lebih fokus ke nilai syari'ah, namun tetap mencantumkan beberapa nilainilai akidah dan akhlak seperti beberapa bacaan doa, dan kata-kata motivasi.

Lebih lanjut Salafudin (2015) juga mengemukakan bahwa beberapa strategi pembelajaran yang dapat dilakukan dalam penanaman nilai-nilai ajaran islam di matematika diantaranya selalu menyebut nama Allah, penggunaan istilah, Ilustrasi visual, aplikasi atau contoh-contoh, menyisipkan ayat atau hadits yang relevan, penelusuran sejarah, jaringan topik, simbol ayat-ayat kauniah. Dan beberapa hal yang dijelaskan tersebut juga sudah terkandung di Handbook yang dikembangkan.

Penelitian ini juga sesuai dengan penelitian Rahmawati dan Rizki (2017), dengan kesimpulan bahwa bahan ajar matematika berbasis nilai-nilai islam dinyatakan praktis dan efektif, namun terdapat hal yang dapat ditambah dalam bahan ajar terutama pada pengaitan nilai-nilai islam, dikarenakan dalam penelitian ini baru menggunakan ayat suci Al-qur'an, dan belum menggunakan riwayat hadis yang dapat menunjang motivasi belajar siswa terkait dengan materi. Terdapat kesamaan materi dan penggunaan nilainilai islam dalam pengembangan bahan ajar tersebut, namun perbedaan yang terdapat dalam dua pengembangan bahan ajar ini terletak pada bentuk bahan ajar. Pengembangan yang telah dilakukan sebelumnya, bahan ajar menggunakan bentuk modul, sedangkan pengembangan ini berbentuk handbook.

\section{KESIMPULAN DAN SARAN}

Berdasarkan penelitian yang telah dilakukan dapat disimpulkan bahwa bahan ajar berbentuk handbook menggunakan pendekatan nilai-nilai islam pada materi aritmatika sosial dinyatkan sangat layak dan praktis digunakan untuk proses pembelajaran.

Penelitian baru diujicoba secara terbatas, sehingga perlu dilakukan penelitian lanjutan untuk mengukur tingkat efektifitas produk di ruang lingkup yang lebih luas.

\section{DAFTAR PUSTAKA}

Andayani, F., \& Lathifah, A. N. (2019). Analisis Kemampuan Pemecahan Masalah Siswa SMP dalam 
DOI: https://doi.org/10.24127/ajpm.v10i1.2140

Menyelesaikan Soal pada Materi Aritmatika Sosial. Jurnal Cendekia, 3(1), 1-10.

Fitriyah, D. N., Santoso, H., \& Suryadinata, N. (2018). Bahan Ajar Transformasi Geometri Berbasis Discovery Learning melalui Pendekatan Etnomatematika. Jurnal Elemen, 4(2): $\quad$ 145-158. https://doi.org/10.29408/jel.v4i2.70 5

Heryuriani, B., \& Musdayati. (2020). Pembelajaran Materi Aritmetika Sosial Dengan Pendekatan STEM. INOMATIKA, 2(2): 147-160. https://doi.org/10.35438/inomatika. v2i2.191

Huda, M., \& Mutia, M. (2017). Mengenal Matematika dalam Perspektif Islam. FOKUS Jurnal Kajian Keislaman Dan Kemasyarakatan, 2(2): 182-199. https://doi.org/10.29240/jf.v2i2.31 0

Khamidah, N. (2013). Pendidikan Karakter dalam Pembelajaran Matematika Di SD Insan Teladan. Al-Bidayah, 5(1): 47-64. https://doi.org/10.14421/albidayah.v5i1.52

Khoiriyah, U., \& Rizki, S. (2017). Pengembangan Bahan Ajar Himpunan Matematika yang Dikaitkan dengan Nilai-Nilai Islam. AKSIOMA: Jurnal Program Studi Pendidikan Matematika, 6(3): 315-322. https://doi.org/10.24127/ajpm.v6i3. 1142

Kurniati, A. (2015). Mengenalkan Matematika Terintegrasi Islam Kepada Anak Sejak Dini. Suska Journal of Mathematics Education. https://doi.org/10.24014/sjme.v1i1. 1326
Maarif, S. (2015). INTEGRASI MATEMATIKA DAN ISLAM DALAM PEMBELAJARAN MATEMATIKA. Infinity Journal. https://doi.org/10.22460/infinity.v4 i2.85

Pamungkas, P., Rizki, S., \& Vahlia, I. (2020). Pengembangan Modul Matematika Berbasis Discovery Learning Disertai Nilai-Nilai Islam. EMTEKA: Jurnal Pendidikan Matematika, 1(1), 110.

Pratiwi, D. D. (2019). Pengembangan Bahan Ajar Aljabar Linier Berbasis Nilai-nilai Keislaman dengan Pendekatan Saintifik. Desimal: Jurnal Matematika. https://doi.org/10.24042/djm.v2i2. 4200

Rahmawati, A., \& Rizki, S. (2017). Pengembangan Bahan Ajar Matematika Berbasis Nilai-Nilai Islam pada Materi Aritmatika Sosial. AKSIOMA: Jurnal Program Studi Pendidikan Matematika.

https://doi.org/10.24127/ajpm.v6i1. 860

Salafudin, S. (2015). Pembelajaran Matematika Yang Bermuatan Nilai Islam. JURNAL PENELITIAN. https://doi.org/10.28918/jupe.v12i2 .651

Sari, A. M., Susanti, N., \& Rahayu, C. (2018). Analisis kesalahan siswa dalam menyelesaikan soal cerita materi aritmatika sosial kelas VII. Journal (Canadian Dental Association).

https://doi.org/10.1007/s13398014-0173-7.2

Siniguian, M. T. (2017). Students Difficulty in Solving Mathematical Problems Marlon. International Journal of Advanced Research in Engineering and Applied Sciences. 
DOI: https://doi.org/10.24127/ajpm.v10i1.2140

Sugiyono. (2012). Metode Penelitian Kuantitatif, Kualitatif dan $R \& D$. Bandung:Alfabeta.

Ulya, K., \& Hayati, Z. (2020). Perkembangan Rasa Ingin Tahu Mahasiswa melalui Pengintegrasian Nilai Islami dalam Pembelajaran Matematika. Jurnal Didaktik Matematika. https://doi.org/10.24815/jdm.v7i2. 17374

Widyaningrum, A. Z. (2016). Analisis Kesulitan Siswa dalam Mengerjakan Soal Cerita Matematika Materi Aritmatika Sosial Ditinjau dari Gaya Belajar Siswa Kelas VII SMP Negeri 5 Metro. Urnal IQRA' : Kajian Ilmu Pendidikan, 1(2), 165-190. Retrieved from https://journal.iaimnumetrolampun g.ac.id/index.php/ji/article/downlo $\mathrm{ad} / 72 / 53 /$ 